Journal of Systems Science and Information

Dec., 2020, Vol. 8, No. 6, pp. 565-577

DOI: $10.21078 /$ JSSI-2020-565-13

\title{
Managing Two-Echelon Remanufacturing Under Patent Protection
}

\author{
Xiaogang CAO \\ School of Management, Wuhan Textile University, Wuhan 430073, China; Key Research Base of \\ Humanities and Social Sciences of Universities in Hubei Province - Research Center of Enterprise \\ Decision Support, Wuhan 430073, China \\ E-mail: caoxiaogang1982@hotmail.com \\ Hui WEN* \\ School of Science, Hubei University of Technology, Wuhan 430068, China \\ E-mail: wen_hui@126.com
}

\begin{abstract}
We propose a two-echelon remanufacturing model in the context of two periods in which the factor of patent protection of the original manufacturer is considered. Through the analysis of the Stackelberg game among the supplier, the original manufacturer and the remanufacturer we obtain the equilibrium solutions of the unit patent licensing fee of the original manufacturer, the recycling effort degree of the remanufacturer, the wholesale price of new and remanufactured core components and the retail price of new and remanufactured products in the second period which are all dependent on the retail price of new products in the first period in cases with patent protection and without patent protection. In the numerical study we analyze the impacts of the remanufacturing rate of used products and the retail price of new products in the first period on the equilibrium results of the second period, and make a comparison between the case with patent protection and the case without patent protection.
\end{abstract}

Keywords remanufacturing management; patent protection; components remanufacturing; stackelberg game

\section{Introduction}

With the intensification of market competition and the increasingly prominent issues of the resources and environment, the enterprises and society have been paying more attention to the recycling and remanufacturing of used products. For example, in the electronic manufacturing industry, Apple, HP, Fuji Xerox and other international well-known enterprises have incorporated remanufacturing into the company's overall strategy in order to achieve the coordinated development of the economy and environment. Xerox Co has saved raw material cost of 200 million dollar in five years through recycling and remanufacturing, and the reusable printer

Received September 12, 2017, accepted July 24, 2020

* Corresponding author

Supported by Major Project of Philosophy and Social Science Research of Universities in Hubei Province (PreFunded Project of Provincial Social Science Fund) (19ZD036), Key Research Base of Humanities and Social Sciences of Universities in Hubei Province-Enterprise Decision Support Research Center Project (DSS20200701) and Key Project of Philosophy and Social Science Research of Education Department in Hubei Province (19D035) 
cartridges produced by HP has generated considerable economic and social benefits. Remanufacturing and closed-loop supply chain have attracted more and more attention in academic and business circles. In fact, not all of the used products collected can be remanufactured, and the core components of many used products have been damaged, which can not be directly used for remanufacturing. In this situation, the damaged core components need to be remanufactured. So we consider a two-echelon remanufacturing model of two periods in which the damaged core components detached from the used products collected by the remanufacturer can be remanufactured by the supplier and then be manufactured into new products by the original manufacturer, and the undamaged core components can be directly manufactured into remanufactured products by the remanufacturer. However, the products are usually patent protected by the original manufacturer, and remanufacturing action has infringed the patent rights of the original manufacturer. There are many cases of infringement of patent rights occurred in remanufacturing business of enterprises. For example, the HP company complained ROT (Repeat-O-Type Stencil Manufacturing Corp) infringe the patent rights of its cartridge, and the court found that the defendant's purchase of the HPs ink cartridge behavior was an act akin to repair, and was not equivalent to remanufacturing, and the court finally decided that the defendant did not constitute infringement. There are many patent infringement cases of remanufactured products such as planer case, clutch case and canvas roof case ${ }^{[1]}$. Thus involving the patent protection factor into our model can help us reveal the pricing mechanism among the decision bodies. Thus we propose the following research questions:

1) What is the impact of two-echelon remanufacturing mode on the pricing decisions of the supply chain members? 2) What is the difference of the pricing decisions between the case with patent protection and the case without patent protection?

Researchers all over the world have studied remanufacturing and closed-loop supply chain problem from many aspects. Savaskan, et al. ${ }^{[2]}$ analyzed the influence of the manufacturer recovery, the retailer recovery and the third party recovery channel structures on the supply chain pricing decisions and profits. Savaskan, et al. ${ }^{[3]}$ analyzed the impacts of manufacturers' direct recycling and two retailers competition recycling of used products on the supply chain channel profit. Debo, et al. ${ }^{[4]}$ studied the problem of joint pricing and production technology selection for new and remanufactured products in a heterogeneous consumer market. Ferrer, et al. ${ }^{[5]}$ discussed the remanufacturing decision problem in three cases of two cycles, multi periods and indefinite planning period under two conditions of monopoly and duopoly market. Ferrer, et al. ${ }^{[6]}$ analyze the remanufacturing and pricing policy in three cases of two cycles, multi periods and infinite planning period under the assumption that there are differences between new and remanufactured products. Ferguson, et al. ${ }^{[7]}$ discussed the pricing and remanufacturing decision making in face of competition threat of remanufactured products. Webster, et al. ${ }^{[8]}$ studied the impact of the government's recycling laws on pricing decisions and profits of manufacturers and remanufacturers in a competitive environment. Mitra, et al. ${ }^{[9]}$ discussed the competitive strategy of manufacturers and remanufacturers from the perspective of government to provide subsidies for recycling and remanufacturing activities. Atasu, et al. ${ }^{[10]}$ analyzed remanufacturing as a marketing strategy for a monopoly manufacturer. Chen, et al. ${ }^{[1]}$ dealt with managing two differentiated versions of the same product by developing analytical models 
using Lagrangean relaxation and dynamic programming schemes. Xiong, et al. ${ }^{[12]}$ established a closed-loop supply chain model in which the original manufacturer licenses the third party to remanufacture through patent protection, and analyze the impact of patent licensing factors on the recycling and remanufacturing of used products. Zhao ${ }^{[13]}$ used the game theory to study the S-M two level closed-loop supply chain composed of one supplier and one manufacturer, and analyze the pricing policy and supply chain system performance in cases of supplier-leading, manufacturer-leading and the equilibrium of the supplier and manufacturer. Ding, et al.[14] studied two kinds of S-M closed-loop supply chain in which the supplier participates in recycling and remanufacturing of components or not under the background of strong supplier, and comparatively analyze the pricing decision and revenue in two cases. The above literatures have studied the topics of remanufacturing competition, optimal decision making and interest coordination of the closed loop supply chain from different perspectives. But the decision-making bodies are all manufacturers, retailers and remanufacturers except Zhao, et al. ${ }^{[13]}$ and Ding, et al. ${ }^{[14]}$, and no literature considers the upstream supplier as the decision-making body. Although Ding, et al. ${ }^{[14]}$ discuss the two-echelon remanufacturing problem in which the supplier participates in remanufacturing of components, but do not involve the patent protection issue.

The contributions of this paper are that we extend the supplier-manufacturer remanufacturing problem through patent protection in two periods, and reveals the pricing mechanism of the supplier, the original manufacturer and the remanufacturer in two-echelon remanufacturing mode. The remainder of the paper is as follows. Section 2 describes the model and assumptions; Section 3 conducts the model establishment and equilibrium analysis with patent protection; Section 4 analyze the case without patent protection; Section 5 is the numerical analysis, and we conclude the paper in Section 6 .

\section{Model and Assumptions}

We consider a two period model consisting of a supplier, an original manufacturer and a remanufacturer. In the first period, the supplier purchases the raw material with unit purchasing price $m$, and manufactures them into new core components with unit manufacturing $\operatorname{cost} C_{s}$, and then wholesales the new core components to the original manufacturer with wholesale price $W_{1 n}$, which are then manufactured into new products by the original manufacturer with manufacturing cost $C$, where we assume one unit of product needs one unit of core component for manufacturing, and then the new products are sold to the market with retail price $P_{1}$, and demand $D_{1}=a-b P_{1}$, where $a>0, b>0, a$ denotes the market capacity, and $b$ denotes the sensitivity degree of consumers to the retail price of products.

In the second period, the supplier also purchases the raw material with unit price $m$ and manufactures it into new core components with manufacturing cost $C_{s}$, but wholesales the new core components to the original manufacturer with wholesale price $W_{2 n}$, and the original manufacturer also manufactures the new core components into new products with manufacturing cost $C$, but sells them to the market with retail price $P_{2}$. At the same time, there is a remanufacturer who collects the used products manufactured in the first period from the market with unit recycling $\operatorname{cost} B$ and recycling effort $\operatorname{cost} C_{\lambda}$ at recycling rate $\delta(0<\delta<1)$, where $\delta=\theta \lambda$, in which $\theta(\theta>0)$ denotes the recycling rate coefficient, which represents the 
recycling efficiency, and $\lambda$ denotes the recycling effort level, and $C_{\lambda}=\frac{k}{2} \lambda^{2}$, in which $k(k>0)$ denotes the recycling effort cost coefficient. At the same time, after the disassembly and detection, $\gamma(0<\gamma<1)$ (which are called remanufacturing rate of used core components) part of used core components disassembled from used products collected by the remanufacturer can be directly used for remanufacturing products, and this part of used core components are manufactured into remanufactured products by the remanufacturer with manufacturing cost $C$ and then sells them to the market with retail price $P_{2}$, where we assume there is no difference in quality and price between new products and remanufactured products in the second period, and all the remanufactured products can be sold out because of the government's advocacy for recycling and remanufacturing. Furthermore, the remanufacturer needs to pay the unit patent licensing fee $f$ to the original manufacturer for each unit of remanufactured products. On the other hand, $1-\gamma$ part of used core components disassembled from used products collected by the remanufacturer can not be directly used for remanufacturing products, and these used core components are bought-back by the supplier with unit buying-back price $A$, and the supplier manufactures the used core components into remanufactured core components with manufacturing cost $C_{s}$, and then wholesales them to the original manufacturer with wholesale price $W_{2 n}$, which are also manufactured into new products by the original manufacturer with manufacturing cost $C$ and are then sold to the market with retail price $P_{2}$.

Furthermore, we assume $m>A>B$, which ensures that the supplier has the incentive to buy-back the used core components that can not be directly used for remanufacturing from the remanufacturer, and the remanufacturer has the incentive to transfer the used core components that can not be directly used for remanufacturing products to the supplier. We use she to refer to the supplier, and use he to refer to the original manufacturer and the remanufacturer. The supplier, the original manufacturer and the remanufacturer are all risk-neutral, and their objectives are all maximizing their own expected profits. We denote $\Pi_{i s}, \Pi_{i m}$ and $\Pi_{i r}$ to denote the profit functions of the supplier, the original manufacturer and the remanufacturer of period $i$ respectively, where $i=1,2$. According to the model description and assumptions we can obtain the optimization problems of the supplier, the original manufacturer in the first period and those of the supplier, the original manufacturer and the remanufacturer in the second period as follows.

In the first period,

$$
\begin{aligned}
& \max \prod_{1 s}\left(W_{1 n}\right)=\left(W_{1 n}-C_{s}-m\right)\left(a-b P_{1}\right), \\
& \max \prod_{1 m}\left(P_{1}\right)=\left(P_{1}-W_{1 n}-C\right)\left(a-b P_{1}\right) .
\end{aligned}
$$

In the second period,

$$
\begin{aligned}
\max \prod_{2 s}\left(W_{2 n}\right)= & \left(W_{2 n}-C_{s}-A\right)(1-\gamma) \theta \lambda\left(a-b P_{1}\right)+\left(W_{2 n}-C_{s}-m\right) \\
& \cdot\left[a-b P_{2}-(1-\gamma) \theta \lambda\left(a-b P_{1}\right)\right],
\end{aligned}
$$




$$
\begin{aligned}
\max \prod_{2 m}\left(P_{2}, f\right)=\left(P_{2}-W_{2 n}-C\right)\left(a-b P_{2}\right)+\left(f-P_{2}+W_{2 n}+C\right) \\
\quad \cdot\left(a-b P_{1}\right) \gamma \theta \lambda \\
\max \prod_{2 r}(\lambda)=\left(P_{2}-B-C-f\right)\left[\gamma \theta \lambda\left(a-b P_{1}\right)\right] \\
+(A-B)\left[(1-\gamma) \theta \lambda\left(a-b P_{1}\right)\right]-\frac{k}{2} \lambda^{2} .
\end{aligned}
$$

\section{Equilibrium Analysis with Patent Protection}

The decision processes of the two periods model are as follows. In the first period, the supplier acts as the Stackelberg leader, and the original manufacturer acts as the Stackelberg follower. The supplier first decides the wholesale price of the new core components in the first period to maximize her own profit, and then the original manufacturer decides the retail price of new products in the first period to maximize his own profit according to the decision of the supplier. In the second period, there are two decision stages, which are as follows: 1) The supplier acts as the Stackelberg leader, and the original manufacturer acts as the Stackelberg follower. The supplier first decides the wholesale price of the new and remanufactured core components in the second period to maximize her own profit, and then the original manufacturer decides the retail price of new products in the second period to maximize his own profit according to wholesale price of the new and remanufactured core components. 2) The original manufacturer acts as the Stackelberg leader, and the remanufacturer acts as the follower. The original manufacturer first decides the unit patent licensing fee in the second period to maximize his own profit, and then the remanufacturer decides the recycling effort level in the second period to maximize his own profit according to the unit patent licensing fee. We first analyze the decisions in the second period, and then analyze the decisions in the first period. As the decision process in the second period is a dynamic game with complete information, there exists the perfect equilibrium solutions. We use the backward induction method to solve the equilibrium solutions.

As the second order derivative of $\prod_{2 r}$ in (5) with respect to $\lambda$ is

$$
\frac{\partial \prod_{2 r}^{2}}{\partial \lambda^{2}}=-k<0
$$

$\prod_{2 r}$ is concave with respect to $\lambda$, so there is optimal solution to (5) with respect to $\lambda$.

Taking the first order condition of $\prod_{2 r}$ in (5) with respect to $\lambda$ we obtain

$$
\frac{\prod_{2 r}}{\partial \lambda}=2 \gamma \theta\left(a-b P_{1}\right)\left(P_{2}-B-C-f\right)+2(A-B)(1-\gamma) \theta\left(a-b P_{1}-k \lambda=0,\right.
$$

so

$$
\lambda(f)=\frac{1}{k}\left[2 \gamma \theta\left(a-b P_{1}\right)\left(P_{2}-B-C-f\right)+2(A-B)(1-\gamma) \theta\left(a-b P_{1}\right)\right] .
$$

Substituting (6) into (4) we have

$$
\max \prod_{2 m}\left(P_{2}, f\right)=\left(P_{2}-W_{2 n}-C\right)\left(a-b P_{2}\right)+\left(f-P_{2}+W_{2 n}+C\right)\left(a-b P_{1}\right) \gamma \theta
$$




$$
\cdot \frac{1}{k}\left[2 \gamma \theta\left(a-b P_{1}\right)\left(P_{2}-B-C-f\right)+2(A-B)(1-\gamma) \theta\left(a-b P_{1}\right)\right] .
$$

We can prove that the Hessian matrix of $\prod_{2 m}$ in (7) with respect to $P_{2}$ and $f$ is semi-negative definite, so $\prod_{2 m}$ in (7) is jointly concave with respect to $P_{2}$ and $f$, and there is optimal solution to (7) with respect to $P_{2}$ and $f$. Taking the first order condition of $\prod_{2 m}$ in (7) with respect to $f$ we can obtain

$$
f=\frac{\gamma\left(2 P_{2}-2 C-W_{2 n}-A\right)+A-B}{2 \gamma},
$$

then substituting (8) into (6) we have

$$
\lambda=\frac{\theta\left(a-b P_{1}\right)\left(\gamma W_{2 n}-\gamma A+3 A-B\right)}{k} .
$$

Now we begin to analyze the decisions of the first stage in the second period, taking the first order condition of $\prod_{2 m}$ in (4) with respect to $P_{2}$ we obtain

$$
P_{2}\left(W_{2 n}\right)=\frac{b W_{2 n}+b C+a-\gamma \theta \lambda\left(a-b P_{1}\right)}{2 b},
$$

then substituting (10) into (3) we have

$$
\begin{aligned}
\max \prod_{2 s}\left(W_{2 n}\right)= & \left(W_{2 n}-C_{s}-A\right)(1-\gamma) \theta \lambda\left(a-b P_{1}\right) \\
& +\left(W_{2 n}-C_{s}-m\right) \frac{a-b W_{2 n}-b C+(3 \gamma-2) \theta \lambda\left(a-b P_{1}\right)}{2} .
\end{aligned}
$$

As the second order derivative of $\prod_{2 s}$ in (11) with respect to $W_{2 n}$ is negative, $\prod_{2 s}$ in (11) with respect to $W_{2 n}$ is concave, so there is optimal solution to (11) with respect to $W_{2 n}$. Taking the first order condition of (11) with respect to $W_{2 n}$ we obtain

$$
W_{2 n}=\frac{a-b\left(C-C_{s}-m\right)+\theta \lambda(3 \gamma-2)\left(a-b P_{1}\right)}{2 b},
$$

then substituting (12) into (10) we have

$$
P_{2}=\frac{3 a+b\left(C+C_{s}+m\right)+(\gamma-2) \theta \lambda\left(a-b P_{1}\right)}{4 b},
$$

then solving (8), (9), (12) and (13) simultaneously we obtain

$$
\left\{\begin{array}{l}
f^{*}\left(P_{1}\right)=\frac{1}{2}\left[\frac{a}{b}+\frac{A-B}{\gamma}-A-C+\frac{\left(a-b P_{1}\right)^{2} \gamma \theta^{2}\left(-6 b B-2 A b(\gamma-3)+\left(a+b\left(C_{s}-C+m\right)\right) \gamma\right)}{b\left[\gamma \theta^{2}(3 \gamma-2)\left(a-b P_{1}\right)^{2}-2 b k\right]}\right], \\
\lambda^{*}\left(P_{1}\right)=\frac{\left(a=b P_{1} \theta\left[6 b B+2 A b(\gamma-3)-\gamma\left(a+b\left(C_{s}-C+m\right)\right)\right]\right.}{\gamma \theta^{2}(3 \gamma-2)\left(a-b P_{1}\right)^{2}-2 b k}, \\
W_{2 n}^{*}\left(P_{1}\right)=\frac{\left(a=b P_{1}\right)^{2} \theta^{2}(3 \gamma-2)[3 B+A(\gamma-3)]-k\left[a+b\left(C_{s}-C+m\right)\right]}{\gamma \theta^{2}(3 \gamma-2)\left(a-b P_{1}\right)^{2}-2 b k}, \\
P_{2}^{*}\left(P_{1}\right)=\frac{3 a+b\left(C+C_{s}+m\right)}{4 b}-\frac{\left(a-b P_{1}\right)^{2}(\gamma-2) \theta^{2}\left[-6 b B-2 A b(\gamma-3)+\gamma\left(a+b\left(C_{s}-C+m\right)\right)\right]}{4 b\left[\gamma \theta^{2}(3 \gamma-2)\left(a-b P_{1}\right)^{2}-2 b k\right]} .
\end{array}\right.
$$

So, we have the following result. 
Proposition 1 In the situation with patent protection, the equilibrium solutions of the unit patent licensing fee, the recycling effort level, the wholesale price of new and remanufactured core components, and the retail price of new and remanufactured products in the second period which are dependent on the retail price of new products in the first period are $f^{*}\left(P_{1}\right), \lambda^{*}\left(P_{1}, W_{2 n}^{*}\left(P_{1}\right)\right.$ and $P_{2}^{*}\left(P_{1}\right)$ in (14), respectively.

Then we analyze the decisions of the first period. In the first period, the supplier acts as the Stackelberg leader, and the original manufacturer acts as the Stackelberg follower. The decision process is as follows: the supplier first decides the wholesale price of new core components in the first period to maximize her own profit, and then the original manufacturer decides the retail price of new products in the first period according to the decision of the supplier to maximize his own profit. This is also a dynamic game with complete information, so there is perfect equilibrium solutions, and we also use the backward induction method to solve it.

We can prove that the second order derivative of $\prod_{1 m}$ in (2) is negative with respect to $P_{1}$, so $\prod_{1 m}$ in (2) is concave with respect to $P_{1}$, and there is optimal solution to (2) with respect to $P_{1}$. Taking the first order condition of $\prod_{1 m}$ in (2) with respect to $P_{1}$ we obtain

$$
P_{1}\left(W_{1 n}\right)=\frac{a+b\left(C+W_{1 n}\right)}{2 b} .
$$

Substituting (15) into (1) we have

$$
\max \prod_{1 s}\left(W_{1 n}\right)=\frac{\left(C_{s}+m-W_{1 n}\right)\left[-a+b\left(C+W_{1 n}\right)\right]}{2} .
$$

We can prove that the second order derivative of $\prod_{1 s}$ in (16) with respect to $W_{1 n}$ is negative, so $\prod_{1 s}$ in (16) is concave with respect to $W_{1 n}$, and there is optimal solution to (16) with respect to $W_{1 n}$. Taking the first order condition of (16) with respect to $W_{1 n}$ we obtain

$$
W_{1 n}^{*}=\frac{a+b\left(-C+C_{s}+m\right)}{2 b} .
$$

Substituting (17) into (15) we have

$$
P_{1}^{*}=\frac{3 a+b\left(C+C_{s}+m\right)}{4 b} .
$$

\section{Equilibrium Analysis Without Patent Protection}

In this section, we discuss the case that there is no patent protection in the second period. The optimization problems in the first period are same as those of the case with patent protection. The optimization problems in the second period are as follows.

$$
\begin{aligned}
& \max \prod_{2 s}\left(W_{2 n}, A\right)=\left(W_{2 n}-C_{s}-m\right)\left[a-b P_{2}-(1-\gamma) \theta \lambda\left(a-b P_{1}\right)\right], \\
& \max \prod_{2 m}\left(P_{2}\right)=\left(P_{2}-W_{2 n}-C\right)\left(a-b P_{2}\right)+\left(W_{2 n}-P_{2}+C\right)\left(a-b P_{1}\right) \gamma \theta \lambda, \\
& \max \prod_{2 r}(\lambda)=\left(P_{2}-B-C\right)\left[\gamma \theta \lambda\left(a-b P_{1}\right)\right]-\frac{k}{2} \lambda^{2} .
\end{aligned}
$$

Now we analyze the decisions in the second period. In this situation, the supplier acts as the Stackelberg leader, and the original manufacturer and the remanufacturer act as the followers. 
The decision process is as follows. The supplier first decides the wholesale price of new and remanufactured core components to maximize her own profit, and then the original manufacturer decides the retail price of new and remanufactured products in the second period according to the wholesale price of new and remanufactured core components to maximize his own profit; Secondly the supplier decides the unit buying-back price of the used core components in the second period to maximize her own profit, and then the remanufacturer decides the recycling effort level to maximize his own profit according to the unit buying-back price of the used core components in the second period. This is also a dynamic game with complete information, so there are perfect equilibrium solutions to the game, and we also use the backward induction method to solve it.

We can prove that the second order derivative of $\prod_{2 m}$ in (20) with respect to $P_{2}$ is negative, so $\prod_{2 m}$ in (20) is concave with respect to $P_{2}$, and there is optimal solution to (20) with respect to $P_{2}$. Taking the first order condition of in $(20)$ with respect to $P_{2}$ we obtain

$$
P_{2}\left(W_{2 n}\right)=\frac{b W_{2 n}+b C+a-\gamma \theta \lambda\left(a-b P_{1}\right)}{2 b},
$$

then substituting (22) into (19) we have

$$
\begin{aligned}
\max \prod_{2 s}\left(W_{2 n}, A\right)= & \left(W_{2 n}-C_{s}-A\right)(1-\gamma) \theta \lambda\left(a-b P_{1}\right) \\
& +\left(W_{2 n}-C_{s}-m\right)\left[\frac{a-b W_{2 n}-b C+(3 \gamma-2) \theta \lambda\left(a-b P_{1}\right)}{2}\right] .
\end{aligned}
$$

We can prove that the Hessian matrix of $\prod_{2 s}$ in (23) is semi negative definite with respect to $W_{2 n}$ and $A$, so $\prod_{2 s}$ in (23) is jointly concave with respect to $W_{2 n}$ and $A$, and there is optimal solution to (23) with respect to $W_{2 n}$, so taking the first order condition of $\prod_{2 s}$ in (23) with respect to $W_{2 n}$ we obtain

$$
W_{2 n}=\frac{a-b\left(C-C_{s}-m\right)+\theta \lambda(3 \gamma-2)\left(a-b P_{1}\right)}{2 b},
$$

then substituting (24) into (22) we have

$$
P_{2}=\frac{3 a+b\left(C+C_{s}+m\right)+(\gamma-2) \theta \lambda\left(a-b P_{1}\right)}{4 b} .
$$

On the other hand, taking the first order condition of $\prod_{2 r}$ in (21) with respect to $\lambda$, we obtain

$$
\lambda(A)=\frac{2 \gamma \theta\left(a-b P_{1}\right)\left(P_{2}-B-C\right)+2(A-B)(1-\gamma) \theta\left(a-b P_{1}\right)}{k} .
$$

Substituting (26) into (19) we have

$$
\begin{aligned}
\max \prod_{2 s}\left(W_{2 n}, A\right)= & -\left(a-b P_{2}\right)+\left(C_{s}+m-W_{2 n}\right) \\
& -\frac{1}{k}\left[2(A-m)\left(a-b P_{1}\right)^{2}(\gamma-1)\left(-A+B+\left(A+C-P_{2}\right) \gamma\right) \theta^{2}\right] .
\end{aligned}
$$

We can prove that the Hessian matrix of $\prod_{2 s}$ in (27) with respect to $W_{2 n}$ and $A$ is semi negative definite, so $\prod_{2 s}$ in (27) is jointly concave with respect to $W_{2 n}$ and $A$, and there is 
optimal solution to (27) with respect to $A$. Taking the first order condition of $\prod_{2 s}$ in (27) with respect to $A$ we can obtain

$$
A=\frac{B+m+C \gamma-\left(m+P_{2}\right) \gamma}{2(1-\gamma)}
$$

Substituting (28) into (26) we have

$$
\lambda=-\frac{\left(a-b P_{1}\right)\left[B-m+\left(C+m-P_{2}\right) \gamma\right] \theta}{k} .
$$

Solving (24), (25), (28) and (29) simultaneously we obtain

$$
\left\{\begin{aligned}
W_{2 n}^{w p^{*}}\left(P_{1}\right)= & \frac{1}{2 b}\left[b\left(-C+C_{s}+m\right)\right. \\
& \left.-\frac{\left.\left(4 a b k+4 a \gamma\left(a-b P_{1}\right)^{2}(2 \gamma-1)-b(3 \gamma-2)\left(4 B-4 m+3 C \gamma-C_{s} \gamma+3 m \gamma\right)\right) \theta^{2}\right)}{\gamma \theta^{2}\left(a-b P_{1}\right)^{2}(\gamma-2)-4 b k}\right] \\
P_{2}^{w p^{*}}\left(P_{1}\right)= & \frac{\left.b k\left(C+C_{s}+m\right)-\left(a-b P_{1}\right)^{2}(\gamma-2)(B+m(\gamma-1)+C \gamma) \theta^{2}-C_{s} \gamma+3 m \gamma\right)+3 a k}{4 b k-\gamma \theta^{2}\left(a-b P_{1}\right)^{2}(\gamma-2)} \\
A^{w p^{*}}\left(P_{1}\right)= & \frac{4 b k(B+m)-k \gamma\left[3 a+b\left(C_{s}-3 C+5 m\right)\right]+2 m \gamma \theta^{2}\left(a-b P_{1}\right)^{2}(\gamma-2)(\gamma-1)}{2(1-\gamma)\left[4 b k-\gamma \theta^{2}\left(a-b P_{1}\right)^{2}(\gamma-2)\right]} \\
\lambda^{w p^{*}}\left(P_{1}\right)= & \frac{\left(a-b P_{1}\right) \theta\left[3 a \gamma+b\left(4 m-4 B-3 C \gamma+C_{s} \gamma-3 m \gamma\right)\right]}{4 b k-\gamma \theta^{2}\left(a-b P_{1}\right)^{2}(\gamma-2)} .
\end{aligned}\right.
$$

Proposition 2 In the situation without patent protection, the equilibrium solutions of the unit buying-back price of the used core components, the recycling effort level, the wholesale price of new and remanufactured core components, and the retail price of new and remanufactured products in the second period which are dependent on the retail price of new products in the first period are $A^{w p^{*}}\left(P_{1}\right), \lambda^{w p^{*}}\left(P_{1}\right), W_{2 n}^{w p^{*}}\left(P_{1}\right)$ and $P_{2}^{w p^{*}}\left(P_{1}\right)$ in $(30)$, respectively.

\section{Numerical Study}

In this section, we use some parameters to analyze the theoretical results above. We set the default values of the parameters as follows: $\theta=0.05, C_{s}=0.5, m=2, C=1, A=1, B=$ $0.5, a=20, b=1, k=0.2, \gamma=0.5, P_{1}^{*}=\frac{3 a+b\left(C+C_{s}+m\right)}{4 b}=15.875$, and we first analyze the impacts of $\gamma$ on the equilibrium solutions in the second period of the case with patent protection and the case without patent protection in Table 1 and Table 2 , respectively.

From Table 1 we can find that in the case with patent protection, with the increase of the remanufacturing rate, the recycling effort degree of the remanufacturer increases, but the retail price of new and remanufactured products in the second period decreases. This is because that with the increase of the remanufacturing rate, increasing the recycling effort degree will lead to the increase of the sales quantity of remanufactured products, which decreases the sales quantity of new products in the second period, so the original manufacturer reduces the retail price of new and remanufactured products to increase the total sales quantity of new and remanufactured products. Whereas, the wholesale price of new and remanufactured core components in the second period decreases firstly, and then increases. The unit patent licensing fee decreases firstly, and then increases, finally decreases. 
Table 1 The impacts of $\gamma$ on the equilibrium solutions of the second period in the case with patent protection

\begin{tabular}{ccccc}
\hline$\gamma$ & $f^{*}\left(P_{1}^{*}\right)$ & $\lambda^{*}\left(P_{1}^{*}\right)$ & $W_{2 n}^{*}\left(P_{1}^{*}\right)$ & $P_{2}^{*}\left(P_{1}^{*}\right)$ \\
\hline 0.1 & 10.22 & 2.51 & 10.31 & 15.63 \\
0.2 & 7.98 & 3.45 & 10.25 & 15.55 \\
0.3 & 6.08 & 4.41 & 10.24 & 15.49 \\
0.4 & 3.34 & 5.39 & 10.30 & 15.43 \\
0.5 & -2.15 & 6.40 & 10.42 & 15.38 \\
0.6 & -21.31 & 7.48 & 10.60 & 15.33 \\
0.7 & 134.70 & 8.65 & 10.84 & 15.30 \\
0.8 & 34.41 & 9.93 & 11.16 & 15.26 \\
0.9 & 24.53 & 11.36 & 11.57 & 15.23 \\
\hline
\end{tabular}

Table 2 The impacts of $\gamma$ on the equilibrium solutions of the second period in the case without patent protection

\begin{tabular}{ccccc}
\hline$\gamma$ & $A^{w p *}\left(P_{1}^{*}\right)$ & $\lambda^{w p *}\left(P_{1}^{*}\right)$ & $W_{2 n}^{w p *}\left(P_{1}^{*}\right)$ & $P_{2}^{w p *}\left(P_{1}^{*}\right)$ \\
\hline 0.1 & 0.47 & 2.85 & 10.25 & 15.60 \\
0.2 & -0.50 & 4.12 & 10.15 & 15.49 \\
0.3 & -1.73 & 5.32 & 10.14 & 15.40 \\
0.4 & -3.36 & 6.63 & 10.20 & 15.33 \\
0.5 & -5.63 & 7.87 & 10.34 & 15.27 \\
0.6 & -9.04 & 9.11 & 10.56 & 15.22 \\
0.7 & -14.71 & 10.34 & 10.86 & 15.18 \\
0.8 & -26.07 & 11.58 & 11.23 & 15.16 \\
0.9 & -60.17 & 12.82 & 11.68 & 15.15 \\
\hline
\end{tabular}

From Table 2 we can find that in the case without patent protection, with the increase of the remanufacturing rate, the unit buying-back price of used core components decreases, the recycling effort degree of the remanufacturer increases, but the retail price of new and remanufactured products in the second period decreases, which is led to by the same reason as in Table 1; whereas, the wholesale price of new and remanufactured core components in the second period decreases firstly, and then increases. Furthermore, we can find that the recycling effort degree of the case without patent protection is bigger than that of the case with patent protection; and the retail price of new and remanufactured products in the second period in the case without patent protection is lower than that of the case with patent protection, which indicates that in the case without patent protection, the original manufacturer and the 
remanufacturer act in Nash game, which avoids the efficiency loss caused in the case with patent protection. Next we analyze the impacts of the retail price of new products in the first period on the equilibrium solutions in the second period of the case with patent protection and the case without patent protection in Table 3 and Table 4, respectively.

Table 3 The impacts of $P_{1}$ on the equilibrium solutions of the second period in the case with patent protection

\begin{tabular}{ccccc}
\hline$P_{1}$ & $f^{*}\left(P_{1}\right)$ & $\lambda^{*}\left(P_{1}\right)$ & $W_{2 n}^{*}\left(P_{1}\right)$ & $P_{2}^{*}\left(P_{1}\right)$ \\
\hline 13 & -2.85 & 10.36 & 9.84 & 14.51 \\
14 & -2.71 & 9.05 & 10.07 & 14.86 \\
15 & -2.48 & 7.67 & 10.27 & 15.16 \\
16 & -2.09 & 6.22 & 10.44 & 15.41 \\
17 & -1.33 & 4.71 & 10.57 & 15.61 \\
18 & 0.39 & 3.17 & 10.67 & 15.76 \\
\hline
\end{tabular}

From Table 3 we can find that in the case with patent protection, with the increase of the retail price of new products in the first period, the unit patent licensing fee increases, the recycling effort degree of the remanufacturer decreases, and the wholesale price of new and remanufactured core components and the retail price of new and remanufactured products in the second period both increase. This is because that with the increase of the retail price of new products in the first period, the sales quantity of remanufactured products in the second period decreases, so the original manufacturer will increase the unit patent licensing fee and the sales price of new and remanufactured products in the second period to increase his own profit, which drives the supplier to raise the wholesale price of new and remanufactured core components in the second period to increase her own profit, and the remanufacturer will decrease the recycling effort degree to save the recycling effort cost.

Table 4 The impacts of $P_{1}$ on the equilibrium solutions of the

\begin{tabular}{ccccc}
\multicolumn{5}{c}{ second period in the case without patent protection } \\
\hline$P_{1}$ & $A^{w p *}\left(P_{1}\right)$ & $\lambda^{*}\left(P_{1}\right)$ & $W_{2 n}^{*}\left(P_{1}\right)$ & $P_{2}^{*}\left(P_{1}\right)$ \\
\hline 13 & -5.12 & 12.46 & 9.66 & 14.24 \\
14 & -5.32 & 10.98 & 9.93 & 14.64 \\
15 & -5.50 & 9.37 & 10.16 & 15.00 \\
16 & -5.65 & 7.65 & 10.37 & 15.30 \\
17 & -5.77 & 5.83 & 10.53 & 15.55 \\
18 & -5.86 & 3.93 & 10.65 & 15.73 \\
\hline
\end{tabular}

From Table 4 we can find that in the case without patent protection, with the increase of the retail price of new products in the first period, the unit buying-back price of used core 
components decreases, and the recycling effort degree of the remanufacturer decreases; whereas, the wholesale price of new and remanufactured core components and the retail price of new and remanufactured products in the second period both increase. This is because that with the increase of the retail price of new products in the first period, the quantity of used core components sold to the supplier and the sales quantity of remanufactured products in the second period both decrease, so the supplier decreases the unit buying-back price of used core components to save her own cost, and the original manufacturer will increase the sales price of new and remanufactured products in the second period to increase his own profit, which drives the supplier to raise the wholesale price of new and remanufactured core components in the second period to increase her own profit, and the remanufacturer will decrease the recycling effort degree to save the recycling effort cost. Furthermore, we can find that the recycling effort degree of the case without patent protection is bigger than that of the case with patent protection; and the retail price of new and remanufactured products in the second period in the case without patent protection is lower than that of the case with patent protection, which indicates that in the case without patent protection, the original manufacturer and the remanufacturer act in Nash game, which avoids the efficiency loss caused in the case with patent protection.

\section{Concluding Remarks}

We establish a two-echelon remanufacturing model in two periods. Through the Stackelberg game among the supplier, the original manufacturer and the remanufacturer in the case with patent protection and the case without patent protection. We obtain the equilibrium solutions of the two periods. Through the numerical analysis we find that in the case with patent protection, the increase of the remanufacturing rate will drive the remanufacturer to increase the recycling effort degree, and the original manufacturer reduces the retail price of new and remanufactured products to increase the total sales quantity of new and remanufactured products. With the increase of the retail price of new products in the first period, the original manufacturer will raise the unit patent licensing fee and the retail price of new and remanufactured products in the second period, and the remanufacturer will reduce the recycling effort degree, and the supplier will raise the wholesale price of new and remanufactured core components in the second period. In the case without patent protection, with the increase of the remanufacturing rate, the supplier will reduce the unit buying-back price of used core components, and the remanufacturer will raise the recycling effort degree of the remanufacturer, and the original manufacturer will reduce the retail price of new and remanufactured products in the second period. With the increase of the retail price of new products in the first period, the supplier will raise the unit buying-back price of used core components and the wholesale price of new and remanufactured core components in the second period, and the remanufacturer will reduce the recycling effort degree of the remanufacturer decreases, and the original manufacturer will increase the retail price of new and remanufactured products in the second period. 


\section{References}

[1] Zhang L. The differentiation of patent infringement between repairs and remanufacturing: Based on Canon Vs. recycle assist recycled cartridges case. Electronics Intellectual Property, 2008(9): 52-55 (in Chinese).

[2] Savaskan R C, Bhattacharya S, Van Wassenhove L N. Closed-loop supply chain models with product remanufacturing. Management Science, 2004, 50(2): 239-252.

[3] Savaskan R C, Van Wassenhove L N. Reverse channel design: The case of competing retailers. Management Science, 2006, 52(1): 1-14.

[4] Debo L G, Toktay B, Van Wassenhove L N. Market segmentation and product technology selection for remanufacturable products. Management Science, 2005, 51(8): 1193-1205.

[5] Ferrer G, Swaminathan J M. Managing new and remanufactured products. Management Science, 2006, 52(1): $15-26$.

[6] Ferrer G, Swaminathan J M. Managing new and differentiated remanufactured products. European Journal of Operational Research, 2010, 203(2): 370-379.

[7] Ferguson M, Toktay L. The effect of competition on recovery strategies. Production and Operations Management, 2006, 15(3): 351-368.

[8] Webster S, Mitra S. Competitive strategy in remanufacturing and the impact of take-back laws. Journal of Operations Management, 2007, 25(6): 1123-1140.

[9] Mitra S, Webster S. Competition in remanufacturing and the effects of government subsidies. International Journal of Production Economics, 2008, 111(2): 287-298.

[10] Atasu A, Sarvary M, Van Wassenhove L N. Remanufacturing as a marketing strategy. Management Science, 2008, 54(10): 1731-1746.

[11] Chen J M, Chang C I. Dynamic pricing for new and remanufactured products in a closed-loop supply chain. International Journal of Production Economics, 2013, 146: 153-160.

[12] Xiong Z K, Shen C R, Peng Z Q. Closed-loop supply chain coordination research with remanufacturing under patent protection. Journal of Management Sciences in China, 2011, 14(6): 76-84 (in Chinese).

[13] Zhao X M, Lin Y H, Su C M. Performance analysis of S-M closed-loop supply chain under different channel power structures. Chinese Journal of Management Science, 2012, 20(2): 78-86 (in Chinese).

[14] Ding B, Ma H Q. Decision-making and performance analysis of S-M closed-loop supply chain with twoechelon remanufacturing. Chinese Journal of Management Science, 2015, 23(6): 118-125 (in Chinese). 